Revista Destaques Acadêmicos, Lajeado, v. 9, n. 3, 2017. ISSN 2176-3070 DOI: http://dx.doi.org/10.22410/issn.2176-3070.v9i3a2017.1360 www.univates.br/revistas

\title{
COACHING NAS ORGANIZAÇÕES: PESQUISA COM GESTORES E AS APROXIMAÇÕES COM A PSICOLOGIA
}

\author{
Márcia Werner ${ }^{1}$, Claudia Werner Johann²
}

Resumo: Este trabalho apresenta uma pesquisa realizada com organizações dos Vales do Taquari e Rio Pardo, Rio Grande do Sul, Brasil, que já participaram de processos de coaching. Os objetivos da pesquisa foram analisar, através de entrevistas com gestores de empresas que contratam o processo, quais os resultados obtidos, bem como a posição dos gestores quanto à qualidade do processo e se o consideram coerente com o que buscavam. A amostra constitui-se de quatro gestores de empresas e a metodologia utilizada foi qualitativa. Para a coleta de dados, foram realizadas entrevistas individuais com os gestores das empresas, e o levantamento e tratamento dos dados se deram através da análise de conteúdo (Bardin, 2011). Trabalhou-se com o referencial teórico sobre a temática do coaching, buscando também as suas bases na área da Psicologia. Os resultados encontrados apontam para a importância do coaching no desenvolvimento pessoal e profissional dos sujeitos, na união das equipes e, ainda, para a satisfação dos gestores e das organizações pesquisadas.

Palavras-chave: Coaching. Pesquisa. Psicologia. Organizações.

\section{INTRODUÇÃO}

Atualmente, o contexto organizacional caracteriza-se por crescente terceirização de serviços e também pela acirrada competitividade, que faz com que as empresas, para sobreviverem, utilizem estratégias como a implementação de tecnologias de ponta, descentralização do processo produtivo e foco no mercado internacional. Essas estratégias permitem um fluxo ágil de materiais e informações, e também transformam, com igual rapidez, as relações e vínculos de trabalho (GRASSI; JACQUES; SCHOSSLER, 2007), dando, assim, espaço para que o Psicólogo entre em cena.

O papel do psicólogo no contexto do trabalho teve três fases, de acordo com Sampaio (2013): Psicologia Industrial; Psicologia Organizacional;

1 Psicóloga (Unisinos), especialista em Violência (USP-SP) e mestre em Psicologia (UFRGS).

2 Acadêmica de Psicologia (Univates). 
e Psicologia do Trabalho. O Psicólogo Organizacional e do Trabalho passou, historicamente, de um profissional responsável apenas por garantir a produtividade da empresa para um profissional mais "humanizado", com um olhar ampliado para além da produção, mas sem perdê-la de vista.

É com este enfoque dicotômico que a Psicologia e outras áreas começaram a pensar e criar estratégias de mudança organizacional, oriundas da Psicologia e de fora dela, como o coaching, que as empresas passaram a contratar, com o objetivo de potencializar o desempenho dos trabalhadores ${ }^{3}$. Neste trabalho, deteve-se a abordar o coaching, que pode ser realizado tanto por um profissional da Psicologia, quanto de outras áreas, contanto que tenha a formação específica para tal. A formação em coaching pode ser buscada, no Brasil, na Sociedade Brasileira de Coaching (SBC), no Instituto Brasileiro de Coaching (IBC), entre outras escolas.

Perguntas como "O que é coaching?", "Para que serve?" ou "Em quais situações pode-se recorrer a ele?" são comuns quando o tema surge à tona, especialmente no curso de Psicologia, mas ainda há muito para se saber. Se buscarmos em artigos de cunho científico, em especial a partir da psicologia, pouco encontraremos em estudos brasileiros.

Marques e Carli (2012) afirmam que, no mundo globalizado, onde qualidade técnica e desenvolvimento profissional são de importância para o sucesso na carreira, problematizações a respeito do próximo passo são muito recorrentes. Alunos em idade pré-vestibular preocupam-se com a profissão a ser escolhida; estudantes de nível superior questionam-se a todo o momento se estão, de fato, no curso certo; profissionais formados ou não, preocupam-se com o futuro de sua carreira e se terão, algum dia, sucesso, ou estão frustrados com a escolha realizada e anseiam por novos caminhos, mas têm dificuldades de descobrir para onde seguir. É aí que o coaching faz a diferença, pois serve como um dispositivo que busca esclarecer essas questões.

O objetivo geral dessa pesquisa foi analisar quais são os resultados obtidos pelas empresas que contratam o serviço de coaching. Como objetivos específicos estão a aproximação entre as temáticas coaching e Psicologia, entrevistar gestores de empresas da região dos Vales do Taquari e Rio Pardo que já passaram pelo processo, analisar os resultados percebidos após o processo nos trabalhadores e na organização, bem como a posição dos gestores quanto à qualidade do processo e se o consideram coerente com o que buscavam.

O coaching é um tema bastante atual, mas possui poucas pesquisas na área da Psicologia, o que fez crescer a vontade de fazer um trabalho que possa aproximá-los um pouco mais. Esta busca se deu, inicialmente, através de um estudo teórico da temática, levando-se em conta os benefícios e possíveis

3 Optou-se pela utilização da nomenclatura trabalhadores, bastante usada pela Psicologia Organizacional e do Trabalho. 
prejuízos do processo, e os apontamentos e questionamentos de diversos autores, além de entrevistas com gestores de empresas que em algum momento já contrataram o coaching para trabalhadores de suas organizações, para que fosse possível medir qualitativamente os resultados percebidos por eles após o processo.

\section{O COACHING}

A utilização do conceito coaching relacionado à administração de pessoal tem, na literatura, origem em dois nomes: Timothy Gallwey e Thomas Leonard. O primeiro, professor de tênis, acreditava que seu papel não era o de criticar seus alunos, mas agir de modo que os fizesse ter ampla consciência do modo como jogavam e assim pudessem fazer os ajustes de que necessitavam. O segundo era contabilista e administrador financeiro e servia não só como consultor financeiro, mas também como bússola para seus clientes, orientandoos no caminho que escolhessem para sua atividade profissional (KRAUSZ, 2007).

Dentre os pressupostos dos quais partem o coaching, Krausz (2007) destaca a importância de fazer perguntas que estimulem o cliente a pensar, ao invés de dar ordens ou comandos, as falhas como possibilidade de aprendizagem, a importância de querer antes mesmo de poder e fazer, entre outros. É um processo que busca uma autonomia do cliente, potencializá-lo para que possa refletir sobre seus valores, crenças e visão de mundo, apoiá-lo na reinvenção e remodelação do pensar e agir, estimulando-o para o desenvolvimento e a aprendizagem contínuos. Aqui, cabe diferenciar as nomenclaturas a ser utilizadas na pesquisa: coaching é o processo, coach é o profissional que o realiza e coachee é o cliente que o contrata.

O coaching não possui uma definição única, sendo caracterizado de diversas formas, por autores diferentes. $\mathrm{O}$ coaching visa a excelência, através da potencialização daquilo que já é muito bom, busca retirar o que incomoda ao coachee e levá-lo ao futuro desejado. É um processo nascido de uma mistura de recursos e técnicas de diversas ciências, como a Psicologia e a Administração, para a produção de mudanças positivas e duradouras que levem as pessoas a atingir suas metas, superar obstáculos e potencializar-se (MARQUES; CARLI, 2012).

Conforme os autores, o coaching pode ser definido pelos termos processo, metodologia e parceria. É através do trabalho realizado em conjunto entre coach e coachee que este último pode realizar um resgate de sua história, de quem se tornou e, olhando para si mesmo, descobrir como viver a vida da forma mais plena e verdadeira. Uma ressalva importante feita por eles é da importância de ter sentimentos verdadeiros em jogo ao longo do processo, mesmo com as conexões e desconexões necessárias. 
Assim como os autores anteriores, Goldsmith, Lyons e Freas (2003) também veem no coaching uma busca pelo sucesso. Os mesmos definem que um dos papéis do coach é ajudar o coachee a enxergar mais longe e ajudá-lo a atingir seus objetivos.

Para Wolk (2008), o coaching objetiva criar possibilidades de ação e fazer com que o coachee assuma o poder que está em suas mãos. É um processo de aprendizagem e de mudança, onde o coach interpreta o facilitador/provocador. $\mathrm{O}$ coaching convida à mudança, a rever os pensamentos, à liderança.

Segundo o autor, o papel do coach é multifacetado. Ele é um facilitador, mas também um detetive, pois deve investigar e seguir os rastros do coachee, reconstruindo seu caminho usando tanto a indução quanto sua intuição. A relação de coach e coachee deve ser íntima e confidencial. O processo tem início, meio e fim, com metas claras e ações determinadas para o alcance dos fins desejados. Pretende-se, ao final do processo, que o coachee seja um conhecedor e observador de si mesmo, que adquira independência nas suas decisões e que assuma responsabilidade e poder.

Segundo Wolk (2008), a aprendizagem e a responsabilidade são ideias fundamentais quando se pensa no coaching. A primeira, porque este é um processo de aprendizagem, onde o coachee abre-se a novas possibilidades de ação em sua vida. A segunda é porque para mudar, é preciso estar ciente de que os obstáculos que o impedem de alcançar seus objetivos estão dentro de si mesmo, não são externos. $\mathrm{O}$ coachee assume a responsabilidade pelas suas falhas e se abre a novas possibilidades de ação que poderão lhe ajudar a atingir suas metas.

Wolk (2008) afirma que as diferentes percepções que temos sobre as pessoas e o mundo se dão porque cada um enxerga a partir do seu olhar e da sua singularidade, depende do tipo de observador que cada um é. Cada observador dará um sentido a uma situação, agirá de acordo com sua observação e obterá um resultado, que pode ou não ser o esperado. Cabe ao observador, quando se deparar com outro resultado que não o que buscava, tentar mudar sua interpretação e agir diferente, e aí entra o coach, para auxiliá-lo nessa jornada.

O coaching não leva em conta o passado do coachee. Seu ponto de partida, conforme Krausz (2007, p. 28) é "onde o coachee se encontra hoje e o que está disposto a fazer para chegar" ao seu objetivo final, sua meta anteriormente pensada.

Percebe-se que, apesar das diferentes definições, todos concordam que o objetivo do coaching é ajudar o desenvolvimento, o atingimento das metas traçadas. É um processo de atuação mútua e ambos coach e coachee devem estar engajados para que seu sucesso seja alcançado. É de importante ter em mente que ao contrário de uma consultoria, em que o consultor indicará soluções e caminhos, no coaching o coach não dará respostas prontas, mas usará técnicas e habilidades que ajudem seu coachee a encontrar as próprias respostas. Acredita- 
se que cada pessoa já possui internamente um campo de sabedoria que lhe permita formular as respostas de que precisa e, com a ajuda do coach, as obterá, frequentemente através de insights (WUNDERLICH, 2013).

O autor afirma ainda que o coachee não pode depender de seu coach e que este último deve sempre pensar na autopotencialização do coachee. Ao longo do coaching, o coachee vai internalizando o processo e passando a dominar boa parte das ferramentas, o que o leva a se tornar um coach de si mesmo e não mais depender da ação de um coach externo.

Wunderlich (2013) define que há dois modos de aplicação do coaching, a saber: o formal, que tem encontros previamente agendados, e o informal, que pode ocorrer a qualquer momento, em qualquer local, e é mais aplicado em ambientes organizacionais. Pode ser aplicado de forma individual ou em pequenos grupos, mas neste último é importante que os coachees tenham livre acesso ao coaching individual, caso tenham necessidade. Quanto ao tema a ser abordado nos encontros, este pode ser definido a priori ou proposto pelo coachee já no encontro.

Ainda segundo o autor, o coaching é um processo sigiloso, mesmo em caso de organizações que o contratem para realizá-lo com seus trabalhadores. Também nestes casos, os trabalhadores não podem ser obrigados a participar do processo e sua implantação deve ser feita através da formação de um grupo de trabalhadores que sejam favoráveis e sustentem sua realização.

Uma das críticas ao coaching é a possibilidade de qualquer pessoa, com ou sem formação, exercer essa atividade, pois não é uma profissão regulamentada. É claro que, pela ética, uma pessoa sem a formação não deveria aplicar o coaching, levando-se em conta que não terá instrução suficiente para lidar com os imprevistos que podem surgir durante o processo. Entretanto, não há punição para as pessoas que exercem o coaching sem formação, visto que essa profissão não possui regulamentação adequada, e cabe ao coachee buscar saber se seu coach possui formação e onde foi feita (WUNDERLICH, 2013).

Para Wolk (2008), o sucesso do coaching depende de alguns fatores, sem os quais poderá ter sério comprometimento e sobre os quais se discorrerá a seguir mais detalhadamente. O processo requer do coach ética pessoal, responsabilidade profissional e alguns pré-requisitos, sendo estes: escuta ativa e reflexiva, intuição, respeito com o outro, centrar-se na transformação ontológica, não dar conselhos, não dizer ao coachee o que fazer ou como agir, eliminar o "tem que", "deveria", "o correto seria", validar a opinião do coachee, não pressionar, empatia e maestria na formulação de perguntas.

Dentre os diversos tipos de coaching, aqui abordaremos alguns, tais como: de carreira, de negócios, Life Coaching, sistêmico, executivo, autocoaching e de equipe ou também conhecido como de time.

O primeiro tipo, o coaching de carreira, aplica-se aos mais diversos contextos e situações de trabalho. Refere-se ao coaching realizado com foco na 
vida profissional do coachee, que pode ser um estudante em fase pré-vestibular em busca da carreira "ideal", um desempregado em busca de um novo emprego, ou até mesmo pessoas já formadas e empregadas em busca de uma carreira que lhe agrade mais. Pode ser realizado dentro ou fora das organizações e é um ramo do coaching em grande expansão (COSTA, 2011a).

Ainda segundo Costa (2011b), o coaching de negócios é um dos tipos menos difundidos nacionalmente. Este tipo de coaching, como o nome já prevê, visa o desempenho de um negócio, através da reeducação dos empreendedores e correção dos rumos da empresa na direção do sucesso e atendendo às necessidades de todos os atores envolvidos: da empresa, do mercado e dos clientes. Pode ser realizado com empreendedores que: a) estejam querendo abrir um negócio; b) que já tenham um negócio, mas estão em busca de melhoria nos resultados; ou c) queiram dar novos rumos ao negócio.

O Life Coaching, de acordo com Marmo (2011) é realizado pelo coach visando uma meta relacionada à vida do coachee, podendo ou não ser no âmbito profissional. A autora contrapõe o life coaching à terapia e orienta que se a pessoa estiver com problemas emocionais, a terapia é a indicada, pois o coach não está apto a tratar esses problemas. O coaching é um processo de desenvolvimento ideal para trabalhar com objetivos e metas para o futuro. Para Pacheco (2011), a terapia trata um distúrbio e busca a cura, enquanto o coaching desenvolve habilidades para ajudar o coachee a lidar com suas limitações.

$\mathrm{O}$ coaching executivo surgiu devido às mudanças organizacionais e na forma como as organizações são geridas. A partir desta alteração do contexto organizacional, viu-se a necessidade também de obtenção de novos estilos de relacionamento entre todos os envolvidos, desde clientes até colaboradores, que passaram de relações hierárquicas de autoridade e subordinação para relações de interdependência, e o foco, que antes era o produto ou serviço, passou a ser o significado que este tem para o consumidor. Entretanto, as tecnologias avançam, mas as empresas pouco mudam (KRAUSZ, 2007).

Ainda conforme a autora, o coaching executivo é uma possibilidade que vem se destacando e caracteriza-se por surtir efeito em toda a organização, causando alterações tanto na estrutura quanto nos processos, comportamentos e aspecto sociocultural da empresa, que acabam facilitando as relações dentro da organização e, por fim, o empenho de todos na busca de resultados que somente de forma coletiva são possíveis. Sua eficácia vem sendo comprovada no mundo inteiro através do desenvolvimento de lideranças que sanam as dificuldades que causariam prejuízo às organizações.

O autocoaching é realizado pela própria pessoa, sem a ajuda de um coach externo. É um grande desafio, pois necessita da pessoa força de vontade, discernimento, responsabilidade e que a pessoa acredite que os obstáculos encontrados são limites temporários autoimpostos, que geram falta de confiança em nós mesmos (Lovisaro, 2011). 
Por fim, há o coaching de equipe. Esse, de acordo com Ricci (2006, p. 31) é também conhecido por team coaching e "é realizado com grupos de pessoas que necessitam desenvolver uma habilidade comum ou desejam montar uma estratégia de consenso". O processo geralmente é contratado pelas empresas para promover uma maior sintonia entre as equipes. Cabe ressaltar que, dentre os tipos de coaching, esse foi o eleito por três das organizações pesquisadas, enquanto a quarta empresa optou pelo coaching executivo.

\section{A PSICOLOGIA E SUA APROXIMAÇÃO COM O COACHING}

O coaching, apesar de não ser um processo exclusivo da Psicologia, possui algumas bases advindas dela. Dentre elas, estão: a Psicologia Positiva, o Humanismo e a Terapia Cognitivo Comportamental (TCC).

O surgimento da Psicologia Positiva é bastante controverso. Seligman e Csikszentmihalyi (2000) afirmam que, independente da origem de suas convicções de que era chegada a hora para uma Psicologia Positiva, o importante é lembrar aos profissionais que Psicologia não é apenas o estudo da patologia, mas também das forças. Afirmam que o tratamento não se dá apenas através do conserto do que está danificado, mas também alimentando o que há de melhor no sujeito e na comunidade.

Whatever the personal origins of our conviction that the time has arrived for a positive psychology, our message is to remind our field that psychology is not just the study of pathology, weakness, and damage; it is also the study of strength and virtue. Treatment is not just fixing what is broken; it is nurturing what is best. Psychology is not just a branch of medicine concerned with illness or health; it is much larger. (...) it tries to adapt what is best in the scientific method to the unique problems that human behavior presents to those who wish to understand it in all its complexity (SELIGMAN; CSIKSZENTMIHALYI, 2000, p. 7).

Paludo e Koller (2007) afirma que dentre os objetivos da Psicologia Positiva está o desenvolvimento de dois segmentos complementares da Psicologia. O primeiro, para prevenir e aliviar os aspectos negativos, e o segundo como promotor de bem-estar. Ou seja, a Psicologia Positiva pretende fazer com que a ciência psicológica focalize as potencialidades e forças humanas, sem com isso ignorar os problemas.

Na Psicologia Positiva, o trabalho deve ser, sobretudo, um emprego gratificante, que se caracteriza por oito benefícios, dentre os quais estão a felicidade e a satisfação, ambiente de trabalho seguro, variedade de tarefas realizadas e renda para a família e para a própria pessoa (SNYDER; LOPEZ, 2009). Ou seja, o trabalho não é só uma renda, mas também fonte de prazer e satisfação, além de outros benefícios. 
Ainda segundo os autores, a satisfação está ciclicamente ligada ao bom desempenho profissional, pois se temos um bom desempenho no trabalho, sentimo-nos mais satisfeitos e, ao passo que estamos mais satisfeitos, melhoramos nosso desempenho profissional. O bom desempenho também está ligado à clareza com que o líder explica os objetivos que devem ser alcançados pelos trabalhadores.

Para os autores, o trabalhador deve se empenhar em fazer do seu trabalho o melhor que ele puder. Caso não seja suficiente para o alcance da satisfação, deve buscar outro trabalho que tenha as características de um emprego gratificante.

Podemos ver aí alguns pressupostos do coaching, que visa basicamente o desempenho, neste caso, profissional. Um dos tipos de coaching, o de carreira, trabalhará pontualmente esta busca pelo desempenho profissional e pelo emprego gratificante, caso tenhamos dúvidas em relação ao trabalho que exercemos.

Outra base do coaching, a TCC, está diretamente relacionada à temática através dos processos cognitivos de processamento representacional e dos aspectos da motivação humana. O primeiro é o cerne da Psicologia Cognitiva e está ligada às representações mentais que "permitem a compreensão do mundo e a própria noção de existência e consciência" (SALDANHA; WAINER, 2011, p. 90). Para os autores, é necessário que todos os métodos de desenvolvimento e compreensão do ser humano tenham ciência da dinâmica dessas representações.

O segundo, aspectos da motivação humana, está ligado ao coaching por ambos os processos contarem com a motivação de seus clientes/pacientes como requisito fundamental. Um paciente que procura terapia necessita de uma postura ativa e participativa durante o processo e de motivação para a resolução de seus conflitos. Da mesma forma, o coachee deve estar motivado a atingir sua meta e disposto a trabalhar em parceria com seu coach. Essa motivação pode ser intrínseca, quando é do desejo do sujeito desenvolver-se ou atingir um objetivo relacionado ao seu crescimento, ou extrínseca, quando a motivação surge como uma necessidade de desenvolvimento demandada por seu ambiente social (SALDANHA; WAINER, 2011).

Hall (1997), em seu texto sobre a vida de Carl Rogers, afirma que este defendia a ideia de que cada pessoa tem a tendência inata a crescer e se desenvolver continuamente. $\mathrm{O}$ resultado disso é que a autoestima e a auto realização do indivíduo são continuamente influenciadas.

Podemos relacionar este ideal do Humanismo ao coaching, pois ambos acreditam que as pessoas querem crescer e se desenvolver, seja em qual for o aspecto de sua vida: pessoal, profissional, espiritual, entre outros. $\mathrm{O}$ foco não deve estar no passado ou na incapacidade, mas naquilo que se quer buscar e conquistar, no que se almeja, e que com os meios certos, se pode conquistar. 
Por essa breve explanação, pode-se perceber que há muitas aproximações entre o coaching e a Psicologia. Percebe-se também que a ideia mais compartilhada entre todos os saberes é a força e a motivação humanas, que fazem com que queiramos sempre melhorar e nos desenvolver, seja profissional ou pessoalmente, e que o coaching é um processo de grande importância para tal.

\section{METODOLOGIA}

Gil (2012, p. 26) define "pesquisa como o processo formal e sistemático de desenvolvimento do método científico". Através do emprego de procedimentos científicos, buscam-se respostas para os problemas levantados pelo pesquisador.

Tendo em vista o objetivo desta pesquisa, optou-se pelo modelo qualitativo que, como afirma Minayo (2010, p. 57), "se conforma melhor a investigações de grupos e segmentos delimitados e focalizados, de histórias sociais sob a ótica dos atores, de relações e para análises de discursos e documentos". No método quantitativo, as respostas ficariam limitadas para a finalidade desta pesquisa e os aspectos subjetivos talvez não pudessem ser levados em conta. Os instrumentos utilizados para a pesquisa foram entrevistas individuais semiestruturadas, por apoiarem-se na sequência das questões, dando assim segurança de que as hipóteses seriam cobertas na conversa e, ainda, cedendo espaço para novas questões (MINAYO, 2010).

A amostra da pesquisa constituiu-se de quatro gestores de organizações dos Vales do Taquari e Rio Pardo, Rio Grande do Sul, Brasil. Como critério de inclusão, as empresas deveriam ter participado e concluído previamente processos de coaching. Não se estipulou, a priori, um número almejado de participantes, mas gostar-se-ia de contar com tantos quanto pudesse. Entretanto, algumas das organizações procuradas ainda não haviam concluído o processo de coaching.

Através de buscas online por coaches das regiões, foi realizado contato e dois coaches indicaram organizações que pudessem participar da pesquisa. Das quatro empresas indicadas, três consentiram em participar da pesquisa. Além dessas, outra empresa, indicada pela orientadora da presente pesquisa, também consentiu na participação.

A pesquisa foi submetida e aprovada pelo Comitê de Ética em Pesquisa da Univates, sob o Certificado de Aprovação de Apreciação Ética (CAAE) de número 39814414.6.0000.5310, sendo aprovado pelo parecer de número 958.123. Ainda, os gestores entrevistados consentiram em participar através do Termo de Consentimento Livre e Esclarecido.

As entrevistas foram realizadas em salas disponíveis dentro das respectivas organizações, gravadas e, posteriormente, transcritas para facilitar seu tratamento que, nesta pesquisa, deu-se através do método de análise de 
conteúdo. Bardin (2011) afirma que esse tipo de metodologia é indispensável para analisar materiais qualitativos, cujo conteúdo é rico e complexo, e que assim é possível interpretar e explorar as questões que surgem nas falas dos entrevistados. Para conceder maior segurança e confiabilidade quanto à categorização, fez-se uso de dois juízes que foram instruídos sobre como proceder na leitura visando à identificação de recorrência de temas (CASTRO, ABS; SARRIERA, 2011). Observou-se que há concordância com a análise realizada pelas autoras.

Para facilitar a discussão do material coletado, este foi organizado em categorias que, de acordo com Bardin (2011), são classes formadas a partir do agrupamento de unidades de registro de características em comum. Para a autora, a categorização pode ser feita de acordo com diferentes critérios e, nesta pesquisa, optou-se pelo semântico, cujo agrupamento é feito com base na temática das categorias.

Durante a transcrição das entrevistas, foi-se observando diversas repetições nas respostas dos gestores, que foram formando as unidades de registro. Tais unidades de registro foram, posteriormente, agrupadas em classes, de acordo com suas temáticas, dando origem às categorias da pesquisa.

\section{RESULTADOS E DISCUSSÃO}

Nesta pesquisa, chegou-se ao agrupamento de três categorias distintas, que serão discutidas individualmente a seguir. A fim de preservar as identidades dos entrevistados, optou-se por chamá-los de Entrevistados A, B, C e D. Cabe ressaltar ainda que as citações serão literalmente fieis às entrevistas, podendo, assim, haver a presença de alguns vícios de linguagem, repetições de palavras e gírias.

\section{O COACHING COMO PROCESSO DE DESENVOLVIMENTO PESSOAL}

A busca pelo coaching nas organizações pesquisadas deu-se não apenas por uma razão. Os gestores trouxeram algumas possibilidades, como a ideia de unir a equipe, de uma melhor compreensão do foco da organização. Entretanto, de forma geral, todos os entrevistados levantaram a questão da busca de desenvolvimento e capacitação: “O que a gente queria era mesmo essa capacitação no desenvolvimento deles" (Entrevistado A).

$\mathrm{Na}$ busca por respaldo na literatura, percebe-se que, apesar das diferentes definições, todos os autores concordam que o objetivo do coaching é ajudar no desenvolvimento, no atingimento das metas traçadas. Goldsmith, Lyons e Freas (2003) afirmam que a busca pelo coaching parte da vontade de se desenvolver e qualificar e que é papel do coach ajudar seus coachees a se tornarem mais do que acreditam que podem ser.

Krausz (2007) afirma que o coaching é um processo que busca uma autonomia do cliente, potencializá-lo para que possa refletir sobre seu pensar 
e agir, estimulando-o para o desenvolvimento e a aprendizagem contínuos. $\mathrm{O}$ Entrevistado A trouxe, em sua fala, essa reflexão citada por Krausz: "O retorno foi (...) muito mais positivo do que a gente tinha pensado, justamente porque ele, ele mexeu a... digamos, com a pessoa em si, sabe? Ele trouxe ã... uma reflexão(...) isso mexeu com eles".

O que parece, ao escutar os entrevistados, é que, apesar de haver a busca por desenvolvimento dos trabalhadores, isso ocorreu de uma forma mais efetiva do que o esperado. Acredita-se que a razão disso seja o fato de que a expectativa dos gestores era de um desenvolvimento a nível profissional, mas o coaching conseguiu trabalhar também com a subjetividade dos trabalhadores. Assim, fez surgir reflexões e mudanças a nível pessoal, tanto quanto profissional.

Ainda, o coaching possibilita a produção de mudanças positivas e duradouras que levem as pessoas a atingir suas metas, superar obstáculos e potencializar-se (MARQUES; CARLI, 2012): "Queria que elas (as equipes) tivessem preparadas psicologicamente, porque eu via que elas tinham potencial, mas elas não acreditavam no potencial delas. (...) e eu queria desenvolver melhor meu trabalho" (Entrevistado B).

Goldsmith, Lyons e Freas (2003) afirmam que a busca pelo coaching parte da vontade de se desenvolver e qualificar. E, tal qual ilustra a fala do entrevistado B, que é papel do coach ajudar seus coachees a se tornarem mais do que acreditam que podem ser.

\section{COACHING: SUPERANDO EXPECTATIVAS}

Como dito anteriormente, dentre os objetivos buscados pelos gestores estavam a capacitação, o desenvolvimento, entre outros. Quando questionados quanto ao atingimento destas metas, a resposta foi unânime: os resultados foram satisfatórios. De acordo com os gestores, os resultados foram tão positivos para as organizações que duas delas já retomaram o coaching e duas estão com planos de fazê-lo.

Para o Entrevistado D, o processo superou as expectativas, gerando um retorno maior do que o esperado. De acordo com ele, essa superação deuse porque os gestores não acreditavam muito, a priori, no coaching nem nos trabalhadores da organização. Segundo ele, a descrença no coaching partia do desconhecimento do processo, o que gerava insegurança, e nos trabalhadores, por não acreditar que eles tivessem tanto potencial para se desenvolver. Entretanto, foi surpreendido por um processo bastante eficaz e pessoas empenhadas em colaborar e se desenvolver.

Cabe ressaltar, ainda, a confiança que os gestores apresentavam em seus coaches. Apesar de não haver verbalizações quanto à sua importância, podese perceber que todos os gestores iniciaram o processo porque confiavam na pessoa do coach, alguns até falam que somente passaram pelo processo pelo fato de o coach ser uma pessoa conhecida e em quem confiavam. 
Araújo (1999, p. 55) afirma que "pela própria natureza, a relação entre coach e cliente requer muita confiança". Para isso, o feedback deve ser constantemente realizado, facilitando a troca de experiências, a mútua compreensão e a abertura. De acordo com a autora, é logo na primeira etapa do processo que se constrói uma parceria sólida, baseada em confiança de ambos os lados e maturidade para assumir as responsabilidades combinadas.

Conforme Chiavenato (2002) há trabalhadores nas organizações com problemas de desempenho e falta de vontade de crescer e melhorar. Para que haja mudança, é necessário que os trabalhadores tenham atitude positiva e motivação para alcançar o crescimento pessoal.

Em confirmação a essa teoria, o Entrevistado $C$ afirmou que, apesar de o processo ter sido satisfatório, poderia ter sido mais positivo e gerado mais resultados se todos tivessem o mesmo empenho na participação. Segundo ele, alguns trabalhadores não têm interesse em se capacitar nem desenvolver e outros tinham dificuldade em acompanhar o processo.

Não foi $100 \%$ satisfatório, mas não pelo processo, mas sim porque algumas pessoas simplesmente não querem. (...) mas de forma geral foi excelente. (...) Porque eu acho que o coaching, ele não pode ser o processo inicial de busca de uma evolução pessoal, de conhecimento, enfim. Ele precisa ser uma das formas, mas não a primeira (...) eu acho que já é pra pessoas que têm um grau de compreensão um pouco mais elevado sobre as coisas (Entrevistado C).

Wunderlich (2013) afirma que no caso de organizações que contratem o coaching para ser realizado com seus trabalhadores, estes não podem ser obrigados a participar do processo. Não se pretende, com isso, julgar o processo realizado na organização do Entrevistado $C$, mas refletir sobre a possibilidade de que, se tivesse sido realizado apenas com os trabalhadores interessados, os resultados poderiam, talvez, ser mais satisfatórios. Ou, ainda, se tivesse sido realizado um trabalho de sensibilização ou preparação para o processo, o resultado poderia ter sido diferente.

Ainda segundo o autor, a implantação do coaching deve ser feita através da formação de um grupo de trabalhadores que sejam favoráveis e sustentem sua realização. Essa questão corrobora com a ideia de que, se tivessem participado apenas os interessados, o processo poderia ter sido mais benéfico para a empresa e para todos os envolvidos.

Certamente, quando há engajamento, os resultados são mais positivos. Sendo assim, deve-se alertar para o fato de que, apesar de haver um ideal de que todos possam passar pelo processo, a fim de que se obtenham resultados a nível global da organização, não se pode exigir que todos se interessem e se empenhem da mesma maneira. Todos são sujeitos subjetivados e portadores de desejos que nem sempre estão de acordo com o restante do grupo. 
Encontra-se em Freas (2003) mais sustentação a essa problematização, quando afirma que, para ser eficaz, o processo tem de ser estratégico e individualizado. Para que haja engajamento e motivação, deve-se adaptar o coaching às necessidades e aspirações individuais de cada sujeito. Ou seja, é necessário realizar uma avaliação prévia para posterior implementação do processo.

Goldsmith (2003) afirma que o coaching pode melhorar o comportamento, mas não soluciona todos os problemas. Salienta que, para que o processo funcione, é preciso que as pessoas tenham vontade e capacidade de mudar, que o ambiente organizacional lhes oportunize essa mudança e que a empresa tenha um rumo direcionado.

Importante ressaltar que, dentre os entrevistados, todos relataram melhoras comportamentais dos participantes do processo: "Diminuiu bastante aquela coisa de intriga (...) O comprometimento deles com a empresa, de acreditar no nosso projeto e de fazer dar certo" (Entrevistado D).

Tal constatação confirma a ideia de Marques e Carli (2012) de que o coaching visa à excelência. O processo retira o que incomoda ao coachee e leva-o ao futuro desejado.

A pesquisa permitiu tomar conhecimento da confiança que os coachees têm em seus coaches. Os gestores afirmaram que, por ser um processo financeiramente custoso, tinham dúvidas quanto à participação. Entretanto, pelo fato de acreditarem na palavra do coach de que o coaching traria retornos significativos, seja em qual âmbito se pretendesse, acabaram aderindo ao processo. Alguns deles estão repetindo o processo ou já repetiram e outros têm planos de voltar a realizar o coaching em suas organizações, pelo sucesso alcançado.

\section{O COACHING COMO POTENCIALIZADOR DE UNIÃO E FACILITADOR DO TRABALHO EM EQUIPE}

Com o surgimento da Era da Informação, o trabalho vem se tornando cada vez mais uma atividade de grupo, ao invés de individual. As equipes estão cada vez mais em alta e a divisão de tarefas dá cada vez mais espaço ao trabalho integrado (CHIAVENATO, 2002). Vê-se essa integração no campo da saúde, do ensino e, é claro, do trabalho.

Moscovici (2002) afirma que na maioria das organizações existem grupos, e não equipes. Há algumas características que diferenciam ambos, dentre elas está o fato de que a equipe entende os objetivos da empresa e todos se engajam para alcançá-los, de forma compartilhada. Há comunicação verdadeira entre os membros, confiança, respeito, cooperação, responsabilidade pelos riscos corridos e, ainda, estimulação de opiniões divergentes. Através da revisão teórica e também da pesquisa com os gestores, pode-se inferir que o coaching é 
um processo que pode auxiliar no desenvolvimento desses aspectos inerentes às equipes.

A busca pela integração das atividades e dos trabalhadores aparece fortemente nas falas dos entrevistados dessa pesquisa, que afirmaram buscar no coaching também a união das equipes: "A ideia que a gente tinha antes era bah, vamos qualificar pra, daqui a pouco, ter esse grupo mais, mais unido e mais fechado" (Entrevistado A). Das quatro organizações pesquisadas, três passaram pelo coaching de equipe e, apenas em uma empresa, o gestor fez o coaching executivo. Todavia, os resultados que este buscava estavam voltados principalmente para a equipe, "da aplicação em si, a ideia de fortalecer as equipes" (Entrevistado B).

Chiavenato (2002) afirma que, a fim de obter sucesso, as empresas devem se assemelhar à orquestra sinfônica. Nessa, há vários instrumentistas tocando em conjunto diversas partituras, de forma integrada e coesa. É assim que deve funcionar uma organização, o todo trabalhando em conjunto. E é a partir de ideia semelhante que os gestores de empresas buscam nivelar suas equipes, uni-las e fazer com que os trabalhadores trabalhem com o mesmo foco. "Então a gente começou a fazer esse trabalho integrado (...) porque a gente igualou a equipe, a gente conseguiu fazer esse nivelamento" (Entrevistado C).

Para Araújo (1999), a organização é a maior beneficiária do processo de coaching. Tal afirmação diz respeito ao ganho no sentido de cooperação e formação contínua e compromisso com resultados por parte dos trabalhadores. O processo, dentro da organização, ajuda os trabalhadores a restabelecer vínculos e a preocuparem-se com o desenvolvimento dos outros. Para o Entrevistado D, o coaching ajudou a unir a equipe, fez com que os trabalhadores passassem a ter mais empatia uns com os outros, repassando responsabilidades e ainda ajudou a alinhar os processos internos da organização.

\section{CONSIDERAÇÕES FINAIS}

Essa pesquisa teve por objetivo analisar quais os resultados obtidos pelas empresas que contratam o serviço de coaching, além de aproximá-lo da Psicologia. Os resultados encontrados são coerentes com o que nos traz a literatura referente à temática.

Dentre esses, o coaching aparece como um processo que auxilia no desenvolvimento pessoal dos coachees. Apesar da busca ter sido, na grande parte das organizações, por um desenvolvimento a nível profissional, o processo resultou em desenvolvimento também a nível pessoal dos entrevistados, proporcionando mudanças comportamentais.

Ainda, percebe-se que o processo foi satisfatório e coerente com as expectativas dos gestores. Dentre as observações dos gestores, consta a importância de os indivíduos estarem motivados a participar do coaching e terem vontade e empenho, caso contrário não atingirão as metas. Não houve, por parte de nenhum gestor, qualquer reclamação quanto ao processo. 
Além disso, surge o coaching como potencializador de união e facilitador do trabalho em equipe. Segundo os gestores, após o processo as equipes encontravam-se mais unidas e capazes de delegar e trabalhar em conjunto, visando o sucesso da organização.

Por fim, encontramos na base do coaching algumas aproximações com a Psicologia. A partir da revisão teórica é possível inferir que o alicerce mais forte está na Psicologia Positiva, principalmente porque tanto a Psicologia Positiva quanto o coaching focam nas forças humanas, buscando as potencialidades dos indivíduos. Todavia, o coaching se apoia fortemente também em conceitos e teorias da TCC, especialmente no aspecto da motivação humana, e da Psicologia Humanista, sobretudo no que concerne ao desejo de crescimento e desenvolvimento.

Dessa forma, mais estudos são necessários para verificar a relação entre a psicologia e o coaching. Outrossim, também é preciso aprofundar estudos empíricos com empresas que já realizaram o processo, a fim de confirmar ou refutar as considerações ora apresentadas, bem como avaliar cientificamente um tema e uma prática cada vez mais comum nas organizações e, por isso, de grande relevância.

\section{REFERÊNCIAS}

ARAUJO, Ane. Coach: um parceiro para o seu sucesso. 8. ed. São Paulo: Gente, 1999.

BARDIN, Laurence. Análise de Conteúdo. São Paulo: Edições 70, 2011.

CASTRO, Thiago Gomes de; ABS, Daniel; SARRIERA, Jorge Castellá. Análise de conteúdo em pesquisas de Psicologia. Psicologia: Ciência e Profissão, Brasília, v. 31, n. 4, p. 814-825, 2011. Disponível em <http:/ /www.scielo.br/scielo.php?script=sci_ arttext\&pid=S1414-98932011000400011\&lng=en\&nrm=iso $>$. Acesso em 12 Jun. 2015.

CHIAVENATO, Idalberto. Construção de Talentos: Coaching e Mentoring. Rio de Janeiro: Elsevier, 2002.

COSTA, Adriano César Rosa da. Coaching de carreira: uma ferramenta indispensável para o sucesso na vida profissional. In: PERCIA, André; SITA, Maurício. (coords.). Manual Completo de Coaching: Grandes especialistas apresentam estudos e métodos para a excelência na prática de suas técnicas. São Paulo: Editora Ser Mais, 2011a.

COSTA, Adriano César Rosa da. Coaching de negócios: uma tendência em evolução no mercado brasileiro. In: PERCIA, André; SITA, Maurício. (coords.). Manual Completo de Coaching: Grandes especialistas apresentam estudos e métodos para a excelência na prática de suas técnicas. São Paulo: Editora Ser Mais, 2011b.

FREAS, Alyssa M. O coaching de executivos para resultados do negócio. In: GOLDSMITH, Marshall; LYONS, Laurence S.; FREAS, Alyssa M. Coaching: o exercício da liderança. Rio de Janeiro: Elsevier, 2003. 
GIL, Antonio Carlos. Métodos e Técnicas de Pesquisa Social. São Paulo: Atlas, 2012.

GOLDSMITH, Marshall; LYONS, Laurence S.; FREAS, Alyssa M. Coaching: o exercício da liderança. Rio de Janeiro: Elsevier, 2003.

GOLDSMITH, Marshall. O coaching para mudança comportamental. In: GOLDSMITH, Marshall; LYONS, Laurence S.; FREAS, Alyssa M. Coaching: o exercício da liderança. Rio de Janeiro: Elsevier, 2003.

GRASSI, Vanise; JACQUES, Maria da Graça Corrêa; SCHOSSLER, Ticiana. A construção das práticas de consultoria em psicologia organizacional e do trabalho. Revista Psicologia: Organizações e Trabalho, 7(1), 57-80, 2007. Disponível em https:/ / periodicos.ufsc.br/index.php/rpot/article/view/2294. Acesso em 20 Mar. 2015.

HALL, Kathy Jo. Carl Rogers. 1997. Disponível em http:/ / muskingum.edu/ psych/ psycweb/history/rogers.htm. Acesso em 20 Mai. 2015.

KRAUSZ, Rosa R. Coaching Executivo: A conquista da liderança. São Paulo: Nobel, 2007.

LOVISARO, Denise. Por que autocoaching? In: PERCIA, André; SITA, Maurício. (coords.). Manual Completo de Coaching: Grandes especialistas apresentam estudos e métodos para a excelência na prática de suas técnicas. São Paulo: Editora Ser Mais, 2011.

MARMO, Alda. Life Coaching ou terapia? In: PERCIA, André; SITA, Maurício. (coords.). Manual Completo de Coaching: Grandes especialistas apresentam estudos e métodos para a excelência na prática de suas técnicas. São Paulo: Editora Ser Mais, 2011.

MARQUES, José Roberto; CARLI, Edson. Coaching de Carreira: Construindo profissionais de sucesso. São Paulo: Editora Ser Mais, 2012.

MINAYO, Maria Cecília de Souza. O desafio do conhecimento: pesquisa qualitativa em saúde. São Paulo: Hucitec, 2010.

MOSCOVICI, Fela. Equipes que dão certo: a multiplicação do Talento Humano. Rio de Janeiro: José Olympio, 2002.

PACHECO, Gilson. Coaching, consultoria e terapia: sacos diferentes da mesma farinha? In: PERCIA, A.; SITA, M. (coords.). Manual Completo de Coaching: Grandes especialistas apresentam estudos e métodos para a excelência na prática de suas técnicas. São Paulo: Editora Ser Mais, 2011.

PALUDO, Simone dos Santos; KOLLER, Sílvia Helena. Psicologia Positiva: uma nova abordagem para antigas questões. Paidéia (Ribeirão Preto), 17(36), 9-20, 2007. Disponível em http:/ / www.scielo.br/scielo.php?script=sci_arttext\&pid=S0103-863X2007000100002\& lng=pt\&tlng=pt. 10.1590/S0103-863X2007000100002. Acesso em 22 Jun. 2015. 
RICCI, Renato. O que é coaching e como ele pode transformar você?. São Paulo: Qualitec Publicações, 2006.

SALDANHA, Marcelo Bravo Cassales; WAINER, Ricardo. Coaching CognitivoComportamental: Apresentação do Modelo. In: WAINER, Ricardo; PICCOLOTO, Neri Mauricio; PERGHER, Giovanni Kuckartz. (colaboradores). Novas temáticas em Terapia Cognitiva. Porto Alegre: Sinopsys, 2011.

SAMPAIO, Jáder dos Reis. Psicologia do Trabalho em Três Faces. In: GOULART, Íris Barbosa; SAMPAIO, Jáder dos Reis. (orgs.). Psicologia do Trabalho e Gestão de Recursos Humanos: Estudos contemporâneos. São Paulo: Casa do Psicólogo, 2013.

SELIGMAN, Martin E. P.; CSIKSZENTMIHALYI, Mihaly. Positive Psychology: An Introduction. American Psychologist. v. 55(1), 5-14, 2000. Disponível em http:/ / psycnet.apa.org/fulltext/2000-13324-001.pdf. Acesso em 23 Out. 2017.

SNYDER, Charles R.; LOPEZ, Shane J. Psicologia Positiva: uma abordagem científica e prática das qualidades humanas. Porto Alegre: Artmed, 2009.

WOLK, Leonardo. Coaching: A arte de soprar brasas. Rio de Janeiro: Qualitymark, 2008.

WUNDERLICH, Marcos. T\&D e coaching. In: BOOG, G. G.; BOOG, M. Manual de treinamento e desenvolvimento: processos e operações. São Paulo: Pearson Education do Brasil, 2013. 